\title{
The Possible Relationship between University Students' Personality Traits, Psychological Well-being and Addiction Potential
}

\author{
Adnan Eshrati Fard ${ }^{1}$, Hooman Rajabi ${ }^{2}$, Ako Delgoshad ${ }^{3}$, Shirin Arjmandi Rad ${ }^{4}, \&$ Saeideh Akbari ${ }^{1}$ \\ ${ }^{1}$ Department of Education Psychology, Kharazmi University, Tehran, Iran \\ ${ }^{2}$ Department of Education Psychology, Tehran University, Tehran, Iran \\ ${ }^{3}$ Department of Psychology of Exceptional Children, Tehran University, Tehran, Iran \\ ${ }^{4}$ Department of Clinical Psychology, Islamic Azad University, Isfahan, Iran \\ Correspondence: Adnan Eshrati Fard, Department of Education Psychology, Kharazmi University, Tehran, Iran.
}

Received: February 11, 2014 Accepted: March 3, 2014 Available online: March 13, 2014

doi:10.11114/ijsss.v2i2.344 URL: http://dx.doi.org/10.11114/ijsss.v2i2.344

\begin{abstract}
The current study aimed to examine the relationship between personality traits, psychological well-being and addiction potential among university students. A total number of 200 BA university students at Kharazmi University of Tehran were selected through stratified sampling. In order to collect the data, the short form of NEO, Ryff Psychological Well-being Inventory and Iranian Addiction Potential Scale were used. To analyze the data, a Pearson product-moment correlation and stepwise regression were conducted. The results revealed a significant negative relationship between psychological well-being and addiction potential. Moreover, a significant negative relationship was found between extraversion, agreeableness, conscientiousness, and openness and addiction potential. However, a significant positive relationship was observed between neuroticism and addiction potential. The results also pointed to psychological well-being, neuroticism, and agreeableness as the strongest predictors for addiction potential, respectively.
\end{abstract}

Keywords: Personality traits, Psychological well-being, Addiction potential, University students

\section{Introduction}

Research has pointed to addiction as one of the socio-psychological problems of the current global community (Flora \& Stalikas, 2012). Addiction is a chronic state as a result of consuming drugs repeatedly which leads to gradual changes in individuals' behavior, feelings, and thinking in which the person loses his/her control and hurts himself/herself or others (Crews, Zou, \& Qin, 2011). Indeed, it is not only a big personal problem and results in both physical and mental consequences for the addicted person, it also is considered as a social problem which threatens the economic, political, social, and cultural health of the society (Roberts et al., 2010). Hence, identifying the factors which might make an impact on individuals' tendency to drugs seems to be of significance.

There are a wide range of internal and external reasons underlying individuals' tendency to drugs. As regards the external factors, we might refer to the family, peers, economic, social and political status of the society (Thompson et al, 2010; Solinas, Thiriet, Chauvet, \& Jaber, 2010; Roberts et al., 2010). Considering the internal factors, we might point to the genetic effect and such factors as depression, stress, self-concept, self-esteem, worldview, psychological well-being, and personality traits (Goodman, 2008; Raisi et al., 2008). However, a large number of researchers conceived of personality as the most crucial underlying factor of getting addicted. It is assumed that addicted people suffer from personality weaknesses which make them more vulnerable to getting addicted (Cheetham, Allen, Yucel, \& Lubman, 2010; Hansen \& Breivik, 2001). Moreover, research has pointed to the psychological well-being as one of the effective factors in individuals' tendency to getting addicted (Roberts et al., 2010; Anderson \& Eisemann, 2003).

Psychologists view personality as a dynamic organization constituted from physio-pyschological systems of an individual which determines one's behavior, interest, viewpoint, and capabilities and allows for anticipating what one might do in a certain circumstance (Per \& Beyoglu, 2011). The structure of the personality has been explained based on several models. One model which has recently received considerable attention is five-factorial model of personality including extraversion (sociable, active, liking others, willingness to participate in communities and ceremonies), agreeableness (sympathy and empathy, cooperation and willingness to communicate with others, and sensitive), neuroticism (having negative feelings such as fear, sadness, arousal, anger, and sinfulness), conscientiousness (controlling the incentives and 
tendencies and employing a planning for behavior), and openness (active imagination, attentive to beauty, attending to internal emotional experiences and independent judgment) (Just, 2011; Haghshenas, 2009).

A large body of research conducted to investigate the role of personality traits (adventure-seeking, aggressiveness, neuroticism) in addictive behavior have indicated that personality traits play a vital role in starting, developing and continuing of addiction (Ball, 2005). In their study, Grana, Munoz and Navas (2004) demonstrated that high scores in neuroticism and low scores in conscientiousness would predict addiction among adolescents (Zargar \& Ghaffari, 2009). In another study, Grana, Munoz and Navas (2009) examined the addicted people's personality traits in two chronic and non-chronic groups and found that those in non-chronic group obtained higher scores in extraversion and agreeableness and openness compared to their counterparts in the chronic group. Conversely, Zargar and Ghaffari (2009) found a significant positive relationship between addiction and extraversion. However, they showed that the extent of one's openness would not influence his/her tendency to drugs. In Walton's (2004) study, addicted people achieved high scores in neuroticism and conscientiousness.

Another factor which is of significance in people's tendency to drugs is their psychological well-being. Psychological well-being is nowadays one of most important concepts in the field of Psychology and is defined as follows: a positive feeling and general satisfaction with life including oneself and others in different areas "e.g. family, job" (Bordbar, Nikkar, Yazdani, \& Alipoor, 2011; Myers \& Diener, 1995). The concept highlights such factors as self-acceptance (positive view toward oneself, valuing and accepting one's different dimensions including both positive and negative characteristics and positive feelings considering the past life), control over the environment (emphasizing on finding and making appropriate contextual structure gearing to one's capability and personal need), individual development and growth (feeling of constant and continuous growth, being opt to new experiences, feeling of development with the pass of time), goal-oriented life (meaningfulness of life in the past and present, having micro and macro goals in life and having purposive thoughts and beliefs), self-regulation (self-confidence, capability to resist to social pressures, internal regulation of behavior and independence), positive relationship with others (capability to sympathize and express emotion, belongingness, intimate and satisfactory communication with others) (Bordbar et al., 2011; Dierendonck, 2007; Ryff, 1989).

In addition, the work of several researchers has supported the significant influence of individuals' psychological well-being on addiction. For one thing, those individuals who lack optimal psychological well-being would be more vulnerable to getting addicted to drugs (Lirad \& verdoux, 2002; Kidorf, 2004; Tostes, 2009; Raisi et al., 2008). In another study, Gasper (2003) demonstrated that individuals with better psychological well-being would perform much better while being confronted with problems and stressful situations (Bordbar et al., 2011).

Addiction to drugs is common among different age ranges (groups). However, the youth are more inclined to drugs (Khushehmehri, Taheri, Tehrani, \& Fatin, 2010). In this group, university students are different from their counterparts in terms of their status and thinking and social prestige both at present and in future. Their high thinking and social prestige would make the society expect less extent of addiction to drugs among them. Yet, some cases of addiction are observed in this group which would bring about worries (Serajzadeh \& Feizi, 2007). Comparing the extent of drug consumption among university students and other social groups is beyond the scope of the current study and needs a separate investigation. Nevertheless, regardless of different aspects of the problem, investigating addiction and the influential factors on it among the university students seems to be of utmost significance. Bearing this in mind and considering the contradictory results with regard to the relationship between personality traits and tendency to addiction, there seems to be an urgent need for studying it.

The current study aimed to examine the possible relationship between personality traits (extraversion, agreeableness, neuroticism, conscientiousness and openness) and psychological well-being and addiction potential among university students. The study specifically addressed the following question:

1) Is there any significant relationship between psychological well-being and five personality traits and addiction potential?

2) Which factors would be stronger in predicting the addiction potential?

3) Do male and female university students differ regarding their addiction potential? (Is there any significant difference among university students' addiction potential in terms of gender?)

\section{Methods}

\subsection{Participants}

The statistical sample included all BA students at Kharazmi University of Tehran in the academic year 2013-2014. Through stratified sampling procedure, 200 university students were selected to be included in the sample. As regards the gender of the participants, 120 male and 80 female students participated in this study. 


\subsection{Instruments}

\subsubsection{Addiction Potential Scale}

The Iranian version of APS was used in this study which was devised by Zargar (2006) considering the socio-psychological condition of Iranian society. The questionnaire includes two components, 36 items and 5 cross-checking (false checking) items. The scoring of each item is on a range of 0 (completely disagree) to 3 (completely agree). The higher score an individual obtains, the higher his/her potential for addiction is and vice versa. As regards the first component, active potential, more items are related to anti-social behaviors, tendency to drugs, positive attitudes towards drugs, and adventure-seeking. With regard to the second component, passive potential, more items are related to lack of assertiveness and depression. The reliability of the questionnaire was calculated through Cronbach alpha as 0.90 which is considered as an optimal level (Zargar, 2006). In the current study, the reliability of 0.88 was obtained through Cronbach alpha.

\subsubsection{Neo Five Factor Inventory (NEO-FFI)}

Devised based on the factorial analysis of NEO-PI scores in 1986 targets five personality traits (extraversion, agreeableness, neuroticism, conscientiousness, openness) of adults. It includes 60 five-point Likert scale from 0 to 4 . Each component (trait) includes 12 items. The minimum and maximum scores for each component are 0 and 48 , respectively. The reliability of the questionnaire was calculated through test-retest method with two-week interval as 0.86 to 0.90 (Mccrae \& costa, 2004). In the current study, the reliability of the questionnaire was calculated through Cronbach alpha as 0.81 .

\subsubsection{Ryff Psychological Well-being Questionnaire}

Devised by Ryff (1989), includes 89 items and 6 components: self-acceptance, environmental control, positive relationship with others, goal-oriented life, individual development, independence. For each component, 14 items are included in the questionnaire. The items of the questionnaire are on a six-point Likert scale from completely disagree $(0)$ to completely agree (5) (Ryff, 1989).reported a reliability coefficient of 0.84 through Cronbach alpha (Dierendonck et al., 2007). In the current study, the reliability of the questionnaire was calculated as 0.86 through Cronbach alpha.

\subsection{Procedure}

In the current study, the questionnaires were administered in groups. In this way, the questionnaires were distributed to the students of different faculties of the university simultaneously. First, the researcher provided the participants with some explanations and ensured them of the confidentiality of their information. It is worth noting that administering these questionnaires took almost two weeks.

\section{Results}

First, Pearson-product moment correlation was used in order to examine the possible relationship between the variables under the study. Table 1 displays the results. Then, in order to determine the proportion of the variables in predicting the addiction potential, multi-step regression was conducted (Table 2). Finally, an independent t-test was utilized in order to examine the possible difference in addiction potential regarding the participants' gender (Table 3 ).

Table 1. Descriptive statistics (Mean and Standard Deviation) and correlation coefficients for the variables under the study

\begin{tabular}{|c|c|c|c|c|c|c|c|c|c|}
\hline & Variables & $\mathrm{M}$ & SD & 1 & 2 & 3 & 4 & 5 & 6 \\
\hline 1 & Psychological well-being & 3.12 & .62 & & & & & & \\
\hline 2 & Extraversion & 3.23 & .58 & $* .73$ & & & & & \\
\hline 3 & Agreeableness & 3.50 & .63 & $* .78$ & $* .68$ & & & & \\
\hline 4 & Conscientiousness & 3.39 & .61 & $* .45$ & $* .41$ & $* .38$ & & & \\
\hline 5 & Openness & 3.17 & .27 & $* .24$ & .07 & $* .19$ & $* .21$ & & \\
\hline 6 & Neuroticism & 2.83 & .63 & $*_{-} .77$ & $*_{-.66}$ & $*_{-} .68$ & $*-.36$ & $*-.24$ & \\
\hline 7 & Addiction potential & .90 & .49 & $*_{-.} .73$ & $*_{-} .56$ & $*_{-.65}(2)$ & $*-.27$ & $*_{-} .12$ & *.67 \\
\hline
\end{tabular}

$* \overline{\mathrm{P}}<0.05$

As Table 1 indicates, there is a significant negative relationship between psychological well- being and addiction potential $(\mathrm{r}=-.73)$. The correlation coefficients also reveal that four componentts of personality traits including extraversion $(\mathrm{r}=-.56)$, agreeableness $(\mathrm{r}=-.65)$, conscientiousness $(\mathrm{r}=-.27)$, and openness $(\mathrm{r}=-.12)$ negatively associate with addiction potential. However, a significant positive correlation was observed between neuroticism and addiction potential $(\mathrm{r}=-.67)$.

In order to explain addition potential based on five personality traits and psychological well-being, stepwise regression was conducted (See Table 2). 
Table 2. The results of stepwise regression for predicting addiction potential based on the variables under the study

\begin{tabular}{lccccc}
\hline Variable & $\mathrm{B}$ & $\mathrm{SEB}$ & $\beta$ & $\mathrm{R}$ & $\mathrm{R}^{2}$ \\
\hline First step & & & & .72 & .53 \\
Psychological well-being & -.58 & .03 & .73 & .75 & .56 \\
Second step & & & -.52 & & \\
Psychological well-being & -.41 & .05 & .27 & .75 & .57 \\
Neuroticism & .21 & .05 & & & \\
Third step & & & -.42 & .24 & \\
Psychological well-being & .33 & .07 &. .16 & & \\
Neuroticism & .18 & .05 & .06 & &
\end{tabular}

As Table 2 illustrates, psychological well-being accounts for $\% 53$ of addiction potential. In the second step, the neuroticism was included and accountability increased to \%56. In the third step, agreeableness was included and accountability reached to \%57. Considering the regression formula, the researcher used a three-step regression. Hence, $\% 57$ of addiction potential is accounted for by these three variables.

Furthermore, in order to see if there is any significant difference among the participants' addiction potentials in terms of their gender, an independent t-test was used (See Table 3).

Table 3. The results of independent t-test for comparing male and female students' mean scores in addiction potential scale

\begin{tabular}{|c|c|c|c|c|c|c|c|}
\hline Variable & Gender & $\mathrm{N}$ & M & SD & DF & $\mathrm{T}$ & $\mathrm{P}$ \\
\hline Addiction & Male & 120 & 44.91 & 21.01 & 98 & 3.75 & .05 \\
\hline potential & Female & 80 & 34.10 & 19.20 & & & \\
\hline
\end{tabular}

As Table 3 indicates, there is a significant difference between male and female university students regarding their addiction potential. Male students are of higher addiction potential than their female counterparts.

\section{Discussion}

The current study mainly strived to investigate the possible relationship between personality traits, psychological well-being and addiction potential. The results indicated that there was a significant negative relationship between psychological well-being and addiction potential. In other words, increasing the psychological well-being would hopefully decrease the addiction potential and vice versa. The findings bear some similarities with those of previous studies (Preau \& Spire, 2007; Kidorf, 2004; Raisi et al., 2008). Considering the definition of psychological well-being, it seems that lack of any goal in life, not accepting oneself, weak resistance to life pressures and problems, lack of positive relationship with others, depression and stress would lead an individual to appeal to addiction (Kidorf, 2004; Tostes, 2009). The university students who suffer from low psychological well-being usually have lower self-confidence and less optimal condition with regard to environmental control and agreeableness with different situations and thereby, they are not able to come up with appropriate solutions gearing to their capabilities and capacities in the face of problems (Bavi \& Borna, 2009). Hence, these people might be vulnerable to drugs as a false painkiller to be disposed of this condition.

The findings also demonstrated that agreeableness and conscientiousness negatively associated with addiction which supports the ones by (Zargar \& Ghaffari, 2009; Pihl, 2007) but contradict with Walton (2004). It seems that university students with lower conscientiousness and agreeableness are less able to communicate positively with others. Accordingly, they might be more inclined to hurt themselves and others, which Seems possible through addiction (Zargar \& Ghaffari, 2009). In addition, such individuals feel less responsible for their behaviors and actions and associate the problems and issues to external factors and thereby, they enjoy less agreeableness with their environment. Lack of their conscientiousness and agreeableness would cause them some problems and they turn to addiction to get rid of them (Martino \& Allister, 1997).

The results of the study also pointed to the significant negative relationship between extraversion and addiction. This is in line with those of Grana, Munoz and Navas (2009) while it is at odd with those of Zargar and Ghaffari (2009), Aliloo, Arji, Bakhshipoor, and Shahjui (2011). It seems that lack of correct and intimate relationship with friends and family, not participating in cooperative ceremonies and activities, lack of emotional and sympathetic relationship with others considering one's problems would lead individuals to feel lonely and depressed and search for a way to get rid of this condition. Hence, an individual might turn to addiction as a false solution for remedy (Raisi et al., 2008).

The findings of the current study also revealed a significant negative relationship between openness and addiction potential. The results support those of previous studies (Grana, Munoz, \& Navas, 2009). However, these results conflicted with those of Zargar and Ghaffari (2009) and Hansen and Breivik (2001). Paying attention to beauty and 
avoiding ugly and forbidden phenomena are among the main characteristics of these people. Considering addiction as a forbidden phenomenon in the society, openness would prevent individuals from being inclined to addiction (Zargar \& Ghaffari, 2009). The results also showed a significant positive relationship between neuroticism and addiction potential. These findings bear some similarities with those of Grana, Munoz and Navas (2009), Zargar and Ghaffari (2009), Pihl (2007). It seems that neurotic university students have such negative feelings as anger, fear, arousal, sinfulness. These people are less capable of controlling their desires and might use drugs and medicine for decreasing their mental pains and controlling their negative feelings (Grana, Munoz, \& Navas, 2009).

It was also found out that male students were more vulnerable to addiction than their female counterparts. These results support those of previous studies (Martino \& Allister, 1997; Sadeghi, 2002). We might speculate from the findings that male students have less control on their desires and aggressiveness in stressful situations. Moreover, compared to female students, they have less sympathy and intimacy with others and rarely share their problems with others (Markus \& Kitayama, 1991). Taking all these issues into account, if they could not overcome these problems, they would be more vulnerable and thereby, more inclined to addiction.

The findings also revealed that neuroticism and agreeableness would account more than the other components for the university students' addiction potential, respectively. This might indicate that psychological well-being of the university students play a more important role in their addiction potential than their personality traits. Among the personality traits, those students who were of high level of neuroticism (having negative feelings such as fear, anger, arousal, anger, and sinfulness) and low level of agreeableness (sympathy, cooperation, willingness to communicate with others) are more vulnerable to addiction. Other personality traits are yet influential and cannot be ignored.

\section{Conclusion}

To sum up, taking into account the results of the current study, we might conclude that university students' psychological well-being and such personality traits as extraversion, agreeableness, Neuroticism, and conscientiousness play a key role in their addiction potential It is the hope of the researcher that those in charge allocate more attention to the role of these factors in the university students' addiction potential and consider them in their planning.

\section{Acknowledgement}

We grab this opportunity to express my heartfelt thanks to Professor Parvin Kadivar and Dr. Ali Asgary for them insightful comments throughout conducting this study. We also thank the Kharazmi University for providing this opportunity for doing the study in this university.

\section{References}

Aliloo, M., Arji, A., Bakhshipoor, A., \& Shahjui, T. (2011). The relationship between personality traits and confronting solution among addicted people with positive HIV. Iranian journal of Medical Sciences, 33(1), 70-78.

Anderson, P., \& Eisemann, M. (2003). Parental rearing and individual vulnerability to dray addiction: A control study in a Swedish sample. Nord Journal psychiatry, 57(2), 147-156.

Ball, S. A. (2005). Personality traits, problems, and disorders. Clinical applications to substance use disorders. Journal of research in personality, 39, 84-102.

Bavi, S., \& Borna, M. R. (2009). The impact of psychological services of rehabilitation period on negative self-concept, stress, depression, and self-esteem of addicted people in Ahvaz. Iranian journal of Knowledge and Research in Applied Psychology, 11(39), 46-53.

Bordbar, F., Nikkar, M., Yazdani, F., \& Alipoor, A. (2011). Comparing the psychological well-being level of the students of Shiraz Payame Noor University in view of demographic and academic performance variables. Procedia - Social and Behavioral Sciences, 29, 663-669.

Cheetham, A., Allen, N. B., Yücel, M., \& Lubman, D. (2010). The role of affective dysregulation in drug addiction. Clinical Psychology Review, 30, 621- 634.

Crews, F. T., Zou, J., \& Qin, L. (2011). Induction of innate immune genes in brain create the neurobiology of addiction. Brain, Behavior, and Immunity, 25, 4-12.

Dierendonck, D. V., Dyaz, D., Rodryguez, R., Blanco, A., \& Jimenez, B. M. (2007). Ryff's Six-factor Model of Psychological Well-being, A Spanish Exploration. Science +Business Media, 87, 473-479.

Flora, K., \& Stalikas, A. (2012). Factors affecting substance abuse treatment in Greece and their course during therapy. Addictive Behaviors, 37, 1358-1364.

Goodman, A. (2008). Neurobiology of addiction an integrative review. Biochemical Pharmacology, 75, $266-322$.

Grana, J. L., Muñoz, J. J., \& Navas, E. (2009). Normal and pathological personality characteristics in subtypes of drug addicts undergoing treatment. Journal of personality and Individual differences, 46, 418-423. 
Haghshenas, H. (2009). Personality Psychology. Shiraz: Medical Sciences University Publication.

Hansen, E. B., \& Breivik, G. (2001). Sensation seeking as a predictor of positive and Negative risk behavior among Adolescents. Personality and individual differences, 30, 627-640.

Just, C. (2011). A review of literature on the general factor of personality. Personality and Individual Differences, 50, $765-771$.

Khushehmehri, G., Taheri, E., Tehrani, H., \& Fatin, S. (2010). Knowledge of and attitude toward ecstasy among the university students of Tehran Scientific-applied Higher Education. Iranian Journal of Medical Sciences, 8(3), 124-133.

Kidorf, M. (2004). Prevalence of psychiatric and substance use disorder in opioid abusers in community syrinye exchange program. Drug Alcohol Depend, 24(2), 15-22.

Lirad, F., \& Verdoux, H. (2002). Effective of comorbid substance use on Neuro psychological performance in subjects with psychotic or mood disorders. Encephala, 28(2), 160-168.

Markus, H. R., \& Kitayama, S. (1991). Culture and the self: Implications for cognition, emotion, and motivation. Psychological review, 98, 224-253.

Martino, S., \& Allister, M. (1997). Alcohol and other drug use at a university in the south eastern united states. Journal of College Student, 31(3), 373-387.

Mccrae, R. R., \& Costa, P.T. (2004). A contemplated revision of new five factor inventory. Personality and Individual Differences, 36, 587-596.

Myers, D. G., \& Diener, E. (1995). Who is happy? Psychological science, 6, 10-19.

Per, M., \& Beyoglu, A. (2011). Personality types of students who study at the departments of numeric, verbal and fine arts in education faculties. Procedia Social and Behavioral Sciences, 12, 242-247.

Pihl, R. (2007). Personality disorders Behavior Disinhibition And addiction: A commentary. Biopsych, 62, 551-52.

Preau, M., \& Spire, B. (2007). Health Related quality of life among both current and former injection drug users who are HIV infected. Drug alcohol depend, 36(2,3), 175-82.

Raisi, F., Anisi, J., Yazdi, S. M., Zamani, M., \& Rashidi, S. (2008). A comparison of mental health and parenting methods among addicted and non-addicted people. Iranian journal of Behavioral Sciences, 2(1), 33-41.

Ryff, C. D. (1989). Happiness is everything, or is it? Explorations on the meaning of psychological wellbeing. Journal of Personality and Social Psychology, 57, 1069-1081.

Roberts, E. T., Friedman, S. R., Brady, J. E., Pouget, E. R., Tempalski, B., \& Galea, S. (2010). Environmental conditions, political economy, and rates of injection drug use in large US metropolitan areas 1992-2002. Drug and Alcohol Dependence, 106, 142-153.

Sadeghi, M. (2002). prevalence of substance abuse among male medical interns in a Tehran university of medical sciences. Journal of Iranian Medicine, 5(1), 50-51.

Serajzadeh, S., \& Feizi, I. (2007). Influential social factors in consuming opium and alchoholic drinks among university student. Iranian Journal of Social Sciences, 3(4), 121-132.

Solinas, M., Thiriet, N., Chauvet, C., \& Jaber, M. (2010). Prevention and treatment of drug addiction by environmental enrichment. Progress in Neurobiology, 92, 572-592.

Thompson, S., Jun, J., Bender, K., Ferguson, K. M., \& Pollio, D. E. (2010). Estrangement factors associated with addiction to alcohol and drugs among homeless youth in three U.S. cities. Evaluation and Program Planning, 33, 418-427.

Tostes, M. A. (2009). The quality of life in HIV infected women is ass a ciated with morality. Aips Care, 16(1), 177-186.

Walton, K. E. (2004). On the relationship between substance use and personality traits: abstainers are not maladjusted. Journal of Research in Personality, 38, 514-535.

Zargar,Y., \& Ghaffari, M. (2009). Simple and multiple relationships between big-five personality dimensions and addiction in university students. Iranian Journal of Publ Health, 38(3), 113-117.

Zargar, Y. (2006). The construction and validity of Iranian Addiction Potential scale. Iranian Journal of Psychology, $6(4), 348-360$.

\section{(c) $\mathrm{EY}$}

This work is licensed under a Creative Commons Attribution 3.0 License. 